\title{
Engine-generated solid particles - a case study
}

Current ecological trends and resulting legislation like European emissions standards Euro 6d or Best Available Techniques are setting new challenges in the field of environmental protection. Since the problem of emissions of particulate matter from diesel engines was solved by the application of diesel particulate filters (DPFs or FAPs) and due to the global dominance of gasoline fuelled passenger cars, particular concern has been focused on improvement of emissions performance of gasoline vehicles, including hybrids, as well as heavy-duty and non-road vehicles. This paper presents the results of preliminary studies on the chemical and physical properties of gasoline engine-generated particles, including nanoparticles. SEM images were presented which allowed identification of the character of particulate matter and estimates of the dimensions of particles. Moreover, the particles were found to be composed of different elements, including $\mathrm{Cu}, \mathrm{Si}, \mathrm{Na}, \mathrm{Ca}, \mathrm{Zn}$ and $\mathrm{P}$, pointing to the origination of these particles from the pistons and lubricant additives.

Key words: engine emissions, particulate matter, nanoparticles, SEM, morphology

\section{Introduction}

Levels of pollution in the ambient air are a significant subject of environmental studies [1, 2]. Emissions related to transportation are of special concern both of scientific, industrial and governmental representatives. The reason for this is that road pollution is a kind of low-stack emission; it is emitted at the level of the human respiratory tract. Legislation motivated by public health concerns forces engine and vehicle designers to overcome the increased emission of harmful compounds and include high efficiency exhaust gas aftertreatment systems in their designs.

The social awareness of emission intensity and air quality is still increasing. From the physical and chemical (or even mechanical) point of view, the combustion processes of organic fuels occurring both in furnaces and the combustion chambers of vehicular engines will never run with emission of a mixture of only carbon dioxide and water vapour as the result. Exhaust gas consists of hundreds (or even thousands) of groups of chemicals and limits for some of them have been defined by various legal polices. The remaining part of exhaust gas components is unregulated. Moreover, among raw exhaust components, gaseous chemicals and solid particles may be distinguished. The components of solid particles - depending on the conditions of the combustion processes - may occur both in the gaseous and PM-bound forms. These aspects cause studies on exhaust emission to constitute a great challenge for chemists and engine designers.

Particulate matter (PM) is an agglomeration of solid particulates suspended in the atmosphere. Particulate matter is characterized by different chemical and physical properties depending on the aerodynamic diameter size of their idealised spherical volumes, and are also characterized by their origin [3]. Once emitted to the atmosphere, particulate matter undergoes many transformations, such as coagulation and condensation, which lead to changes in the physical and chemical character of aerosols. The formation of particulate matter begins with a nucleation process which occurs in the presence of so-called gaseous precursors, like
$\mathrm{SO}_{2}$ or volatile organic compounds (VOCs). Aerosols may be transported long distances and be gravitationally deposited or removed via rainfall [4]. Atmospheric aerosols are a mixture of particulate matter from many different sources - natural and anthropogenic, with the latter category including material from both stationary and mobile sources [5]. This paper deals with studies on engine generated particulate matter from mobile sources (road vehicles).

Actions resulting in decreased harmful exhaust emissions from combustion engines have been undertaken for decades and have chiefly relied on the application of three ways catalysts (TWCs) and diesel oxidation catalysts (DOCs), followed by Diesel particulate filters (DPFs) [6]. Selective catalytic reactors (SCR), gasoline particulate filters (GPFs) or lean $\mathrm{NO}_{\mathrm{x}}$ trap systems are quite new solutions fitted to recent Diesel and gasoline engines (Fig. 1a and Fig. 1b).

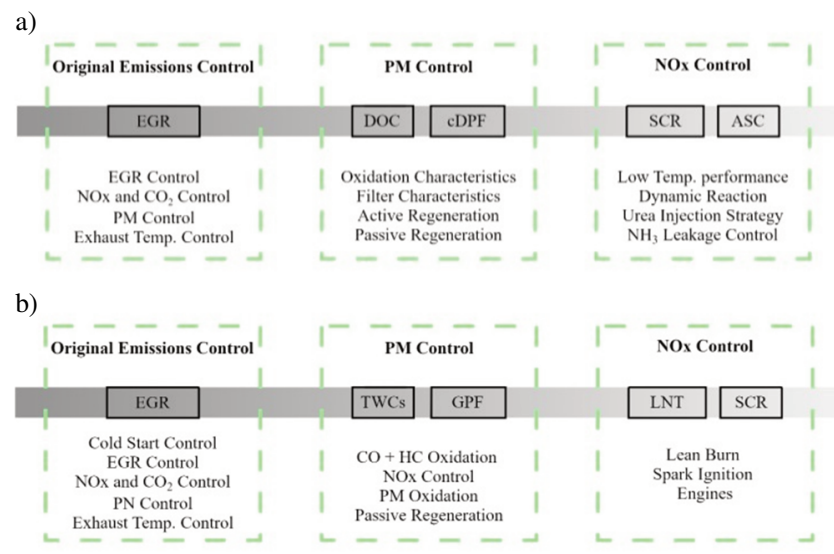

Fig. 1. Technical points of a) diesel engine after treatment system; b) gasoline DI engine after treatment system

Further concern centred on solid particles present in exhaust gas, which resulted in the implementation of new emission standards (Euro 5) where limits for the emission 
of particulate matter mass (PM) and particulate matter number $(\mathrm{PN})$ were set as $4.5 \mathrm{mg} \cdot \mathrm{km}^{-1}$ and $6 \cdot 10^{11} \# \cdot \mathrm{km}^{-1}$, respectively. (Previously, Diesel engines had been subject to mass-based PM limits for emissions of particulates, but with much higher emissions limits and no PM limit). The highest concentrations of PM were reported for diesel engines, for reasons linked to the properties of that fuel and the Diesel cycle, as well as the full roll-out of direct injection for all modern Diesel engines. Therefore, diesel particulate filters (referred to as DPF or FAP) are currently installed to all new diesel-fuelled vehicles. According to the latest update of emission legislation set out in September 2017, newly-produced vehicles should be tested in real driving conditions as part of the type approval procedure [7], later extending to surveillance of vehicles currently in circulation. The abovementioned exhaust aftertreatment systems for control of particles (DPF/FAP, GPF) are mostly designed to work in a "storage and release" manner. This phenomenon is considered a significant source of NPs emission $[8,9]$. The "storage and release" principle relies on regeneration events, which are expected to be more common in real driving conditions due to engine loading and the fact that the temperature of exhaust gas and thus the aftertreatment system elements is continuously changing [8].

This work aimed to identify the main challenges concerning research on solid particles generated by gasoline and new advanced vehicular engines on the basis of literature and own preliminary studies.

\section{Nanoparticles - physical and chemical properties}

A nanoparticle is considered as a particle whose aerodynamic diameter does not exceed $100 \mathrm{~nm}$. In some literature references nanoparticles are described as such particles, but with a diameter range from 10 to $23 \mathrm{~nm}$. This is mostly combined with legal requirements which currently specify the obligatory to control the level of particles emitted of diameter $(23 \mathrm{~nm}-10 \mu \mathrm{m})$. Nowadays, due to the minute size of NPs, research on automotive generated particles is focused on the development of methods enabling the characterization of NPs in terms of their physical and chemical properties [10, 11]. Nanoparticles which are the part of the nucleation mode are the subject a great attention of scientists and engine designers, mainly due to their strong impact on human health [12]. They are able to diffuse through the skin and be transported by the blood reaching the most vital systems and organs.

Similarly as in the atmosphere, nanoparticles, once generated as a result of favourable conditions in an engine combustion chamber undergo reactions of accumulation and coagulation changing the size of spheres and changing the chemical and physical properties [10]. It is believed that the increasing concentration of $\mathrm{SO}_{2}$ and the increase of $\mathrm{SO}_{2}$ conversion enhance NPs' formation [8]. This stage of NPs' formation is known as nucleation. While NPs consist of water, sulphur compounds ad hydrocarbons, larger particulates (accumulation mode and upwards) are made of solid agglomerated soot, which as a material is extremely effective at absorbing and adsorbing organic and inorganic exhaust components (Fig. 2).

\section{Exemplary composition of particles}

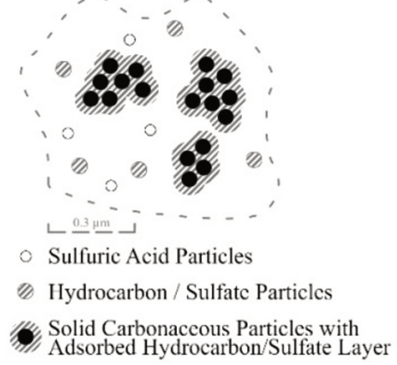

Fig. 2. Typical composition and structure of engine exhaust particles [10]

The influence of the fine solid particles on human health increases in inversely proportion to their size. Research confirms that particles from the $\mathrm{PM}_{2.5}$ category are characterized by greater health affect than $\mathrm{PM}_{10}$. Particles under a diameter of $2.5 \mu \mathrm{m}$ are able to penetrate the blood-air barrier (alveolar-capillary barrier) and to circulate with the blood throughout the human body [12]. Engine generated particles are mostly composed of soot and elemental carbon, which are materials with excellent absorptive properties. As a result, such particles are carriers of absorbed and adsorbed chemicals, including carcinogenic and mutagenic products of chemical reactions occurring in the combustion chamber. Benzo(a)pyrene is the most well-known polycyclic aromatic hydrocarbon (PAH); however, new advance instrumental methods allow investigation of nitric (nitroPAHs) and oxidative (oxy-PAHs) derivatives of PAHs which are considered more dangerous than PAH themselves [13]. The World Health Organization (WHO) has estimated that $\mathrm{PM}$ is responsible for about $3 \%$ of deaths caused by failure of the respiratory system and $5 \%$ of deaths caused by lung cancer [14]. The mechanisms of NPs' negative imapcts on human health are still the subject of many studies. One such mechanism relies on the strong impact of organic matter's oxidative stress on an organism's cells [15].

\section{Nanoparticles' morphology}

SEM analyses allow the morphology and dimension of NPs to be studied. Solid particles' morphology and external structure were analysed using a field emission scanning electron microscope (SEM, FEI Versa 3D) equipped with an energy dispersive X-ray spectrometer (EDS, EDAX Apollo XP) for qualitative physicochemical analysis. SEM observations were carried out without conductive coating at high vacuum mode, using a secondary electron (SE) or backscattered electron detector (BSE) at an acceleration voltage of $5 \mathrm{kV}$. EDS analyses were performed an acceleration voltage of $20 \mathrm{kV}$. For efficient generation of X-rays, the overvoltage must be not less than twice the critical ionization energy of the elements of interest [16].

Figure $3(a, b)$ and Figure $4(a, b)$ present electronic microscopic images of two samples of soot particles sampled on glass-fibre filters during a laboratory emission test (WLTP) of a passenger car with a 1.4 litre gasoline engine. The images were taken at different magnifications. Figure 3a shows particles of ca. $5 \mu \mathrm{m}$ of size. There are rather spherical in shape and seem to be a separate body beyond the rest of particulate matter. The higher magnification 
image (Fig. 3b) presents the rare filament-like particles containing branched structures with very low dimensions of ca. $50 \mathrm{~nm}$. Engine exhaust particles show a strong tendency to accumulate in loose, powdery, brittle agglomerates varying in size. All particle fractions contained nanoparticles down to $100 \mathrm{~nm}$ in the form of agglomerates. The size of these structures is probably even lower, however at this point more exact analysis of the scales present was not possible.

Figures $4 \mathrm{a}$ and $4 \mathrm{~b}$ similarly show the particles generated during operation of gasoline engine. The content of oxygenated additives in the fuel were different comparing to the test mentioned previously. This information is reserved by the fuel producer. Figure $4 \mathrm{a}$ presents a particle of an irregular shape, yet with rather smooth surface. The higher magnification image showed that this surface is rather lumpy, consisting of many minute particles (of 30-70 nm dimension) combining in larger agglomerates. Moreover, as noted by Yang et al. (2016), the nanostructure of particulate matter is highly dependent on the fuel oxygen content [17].

Nanoparticles are usually generated in high-temperature well-premixed processes. These conditions are favourable for soot particles to coalesce in the form of chains. Accord- ingly to the studies of Potenza et al. (2019), the coalescence of particles is possible due to the pressure of charged radicals in the flame. As the flame extinguishes, the free charges disappear and chains coalesce resulting in larger agglomerates [18].

\section{Nanoparticles' chemical composition}

In order to pinpoint the dangers posed by nanoparticles and to accurately recognize solutions enabling the reduction of NP emissions, it is necessary to characterize their chemical composition. Solid particles, regardless of the size mode, are mainly made of organic and inorganic fractions. The organic fraction mainly consists of elemental carbon (EC) and organic carbon (OC). Organic matter is a mixture of hundreds (or even thousands) of organic compounds, beginning with n-alkanes, ending with more complex structures as polycyclic aromatic hydrocarbons (PAHs), their oxygen and nitric derivatives, aldehydes, hopanes and steranes $[19,20]$. The inorganic fraction mostly consists of metals and non-metals and are the effect of material attrition or grinding [20]. The chemical composition of NPs differs depending on many factors, like the fuel used or the engine operating parameters $[11,21]$.
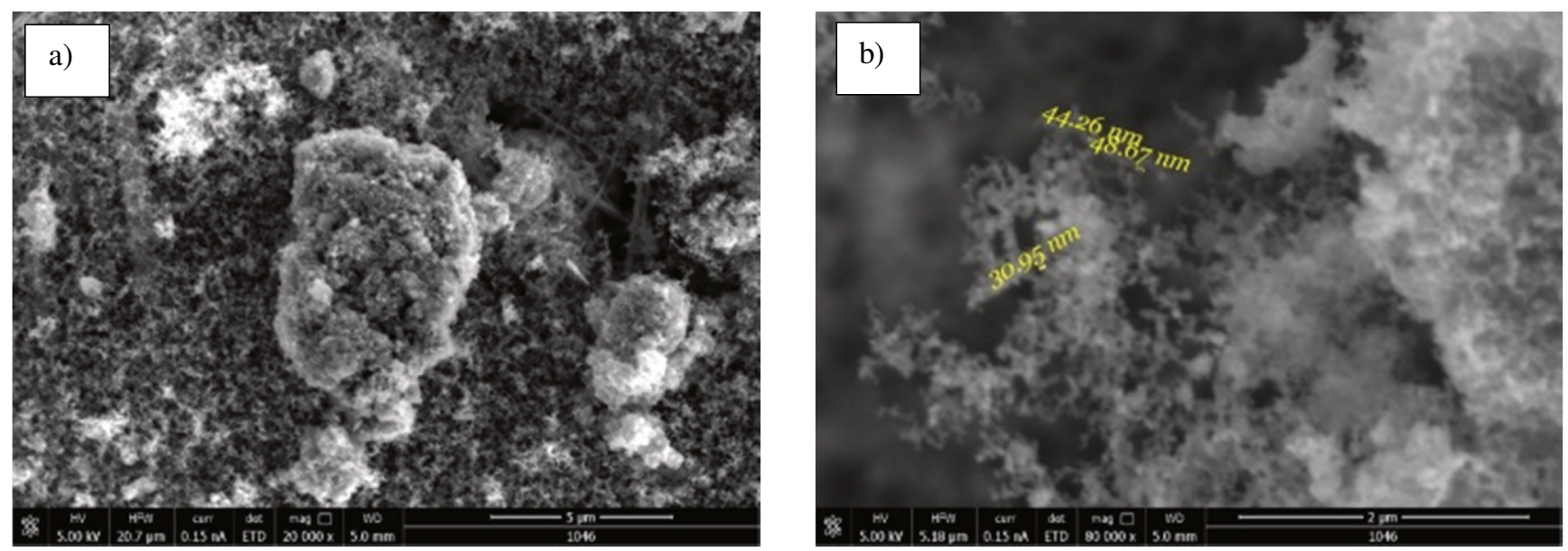

Fig. 3. SEM images of engine generated particles at different magnifications (a: $20000 \mathrm{x}$; b: $80000 \mathrm{x}$ )
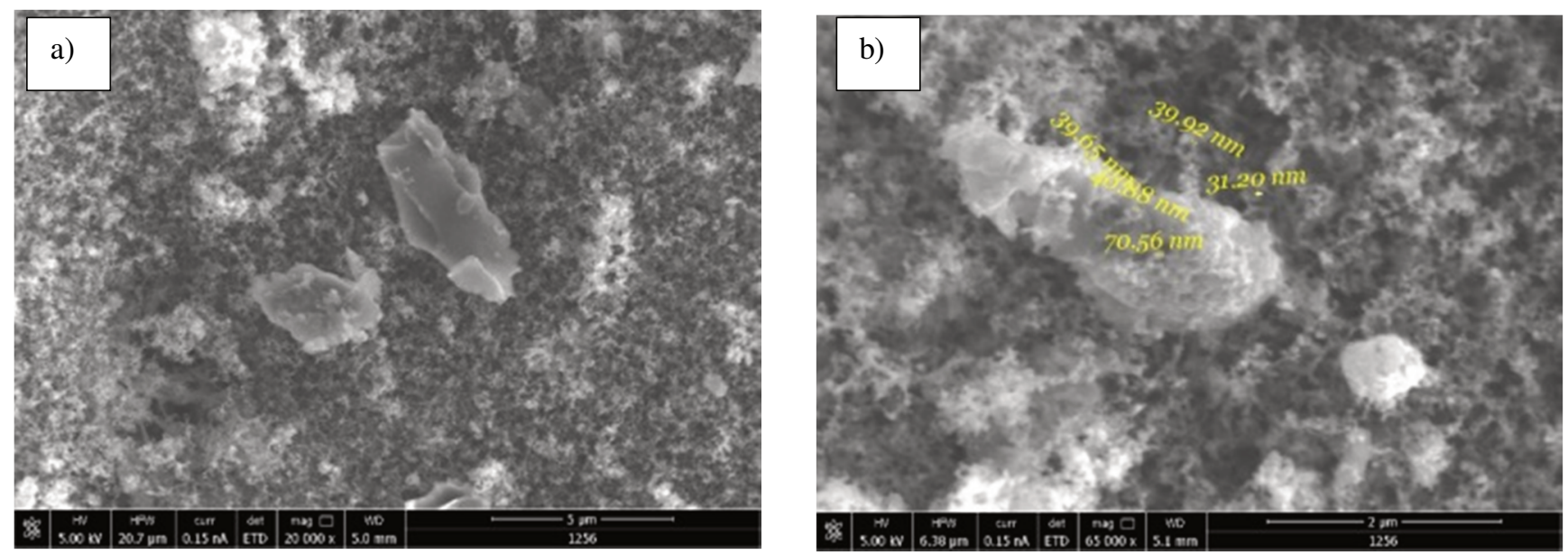

Fig. 4. SEM images of engine generated particles at different magnifications (a: $20000 \mathrm{x}$; b: $65000 \mathrm{x}$ ) 

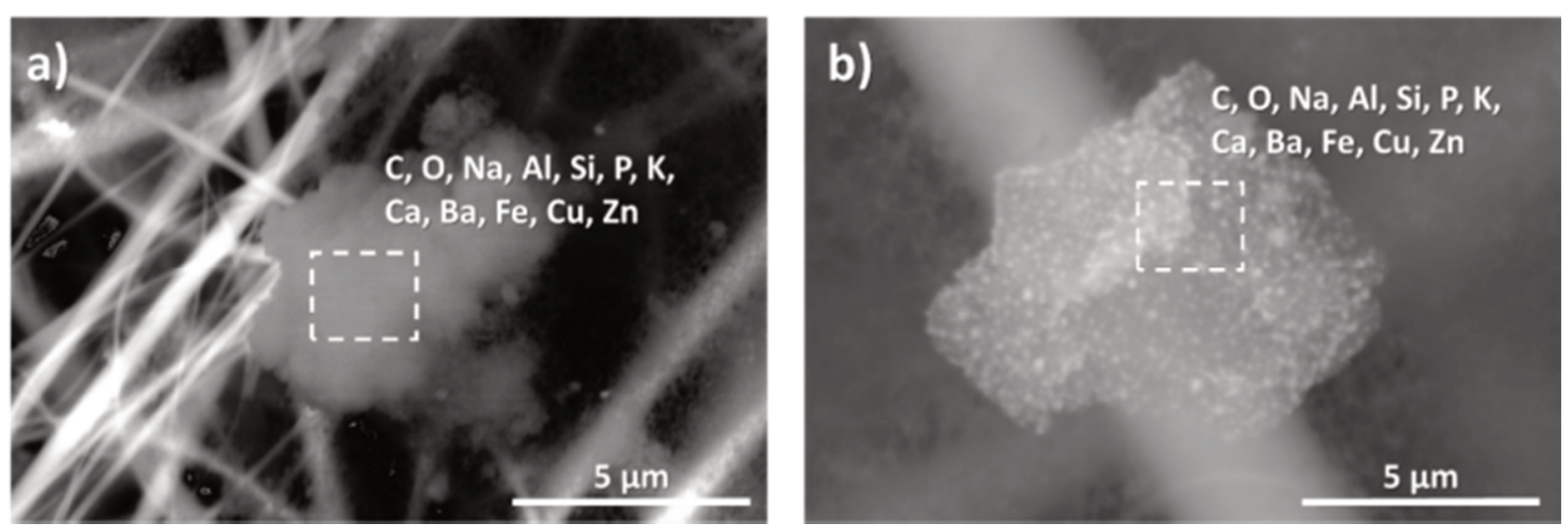

Fig. 5. BSE micrographs of particles with areas for EDS analysis marked a) sample no. 1046 b) sample no. 1256

Figure 5 shows BSE micrographs with results from the qualitative analysis of chemical composition of particulate matter from a gasoline fuelled engine. EDS analysis revealed the presence of $\mathrm{Na}, \mathrm{Ca}, \mathrm{K}, \mathrm{P}, \mathrm{Zn}, \mathrm{Cu}, \mathrm{Ba}$ and $\mathrm{S}$ in all fractions, which come from lubricant additives and minor $\mathrm{Fe}, \mathrm{Al}, \mathrm{Si}$ elements $[18,22]$. The elements can be a part of aluminosilicate, which is composed of $\mathrm{Si}, \mathrm{Al}, \mathrm{Ca}, \mathrm{K}$ and minor levels of $\mathrm{Na}, \mathrm{Mn}$ and $\mathrm{Zn}$ [23]. Moreover, $\mathrm{Cu}$ and $\mathrm{Si}$ are rather bonded into an alloy, being the composite used in pistons $\left(\mathrm{AlSi}_{12} \mathrm{Cu}_{3} \mathrm{Ni}_{2} \mathrm{Mg}\right)$. The areas rich in Ba presented chemical associations of barite $\left(\mathrm{BaSO}_{4}\right)$. The presence of these particles is related to non-exhaust vehicular emissions mainly from brake pads' abrasion emissions. Given that asbestos has been substituted in the compositions of such components, it could explain the sulphur and oxide content associated with these phases which are rich in barium [24]. As the sample was taken from exhaust gas, the presence of material related to brake dust suggests a substantial contribution of particulate from ambient air in the exhaust gas; this material appears to enter the engine with the intake air. Such a phenomenon underlines the need for careful consideration of the precise origin of particulate present in vehicular exhaust, as well as the need for chemical analysis at the nano scale, right down to analysis of individual parts of a structure.

To deepen the studies, TEM and XPS analysis of engine-generated particles and their morphology and chemical composition demanded. These techniques will allow the process of nanoparticles formation to be traced and to find out the valency of elements detected, which would give detailed information on the chemical composition of nanoparticles.

\section{Parameters influencing NP emissions}

Considering NPs of automotive origin, they primarily originate from the powertrain as the result of incomplete fuel combustion process. While leaving the exhaust pipe, due to the temperature gradient or reactions with other substances, some of the exhaust components may undergo aerosol transformations (i.e. condensation reactions), leading to the formation of secondary NPs. Beyond combustion generated NPs, there are also nanoparticles being the result of lubricating oil consumption and road traffic wear, which is the combined physicochemical alteration of material from tires, brakes, clutch mechanisms and the road surface itself.
The share of the fine particles whose material origin lies in the engine lubricant can reach up to $30 \%$ of total enginerelated solid nanoparticles [25-28]. The share of the solid particles emitted whose material origin lies in the oil can be measured by analysis of the zinc and molybdenum concentration. Both metals are present in the quite high amounts in the engine lubricant but they are absent in the fuel; therefore it is estimated that average share for solid nanoparticles is about $10-20 \%$. Additionally, the literature shows that motor oil is responsible for even $30 \%$ of the produced higher hydrocarbons (which are not included in the solid NP fraction). This is caused by their high activation energy for the combustion reaction (at least in comparison to fuel), due to which their combustion during engine combustion cycle is difficult $[28,29]$. To estimate NP emissions originating from the engine oil, it is possible to use measurements of hopanes and steranes in the exhaust [30].

Road traffic wear NPs might be a result of tires grinding on the road and brake pads grinding on brake discs [31]. In light duty vehicles two types of brakes are currently installed: drum and disc. Drum brakes represent older technology; they are heavier and require a greater surface for a sufficient braking force. Moreover, due to their closed construction they often overheat, which decreases their effectiveness. Disc brakes are gaining popularity due to their lower weight, greater resistance to overheating due to their open construction and shorter braking distances [31]. Research has shown that new disc brakes generate more solid particles $\left(\mathrm{PM}_{10}\right.$ and smaller) during to their break-in period. The chemical composition of such PM strongly depends on the material which brakes are constructed of, i.e. iron and copper particles originating from the brake pads or other solid metal particles from the disc. The braking process may be responsible for as much as $50 \%$ of the non-exhaust road traffic emissions [32]. The amount of solid nanoparticles originating from the tires depends on tyre hardness and road abrasiveness. The literature reports that over a distance of $1 \mathrm{~km} 1 \cdot 10^{11}$ solid nanoparticles of this type can be emitted [10,33] and thus the level of NPs of this type is often broadly comparable to the level of exhaust NPs. As mentioned previously, the presence of material assumed to drive from brakes in exhaust particulate complicates the situation regarding qualitative chemical analysis, as a single particle could contain a cocktail of elements deriving from many different sources (fuel, lubricant, engine hardware, intake air particulate). 
In Scandinavian countries, especially in the winter, tires with studs are often used for the purposes of obtaining better grip on a road covered by snow or a layer of ice. Containing tungsten carbide, cobalt or copper, such studs may contribute to NP formation at the tyre-road interface [34]. Elements linked to road salt may also be detected in chemical analyses of exhaust particulate.

Returning to combustion-generated NPs, engine architecture is an important factor influencing the concentration of emitted NPs. The application of gasoline direct injection technology improves fuel consumption and power density, but on the other hand, causes the generation of higher amount of NPs comparing to the amounts of NPs generated where port fuel injection technology is applied (all other factors being equal) [27]. The elevated emission of NPs is probably the result of incomplete combustion in an engine chamber [10, 29]. To reduce emissions, the number and size of the cylinders was reduced in many designs. This trend is called downsizing. However, current technological development requires the optimization of engines from many points of view simultaneously (fuel consumption, emissions, drivability, durability), which is leading to a trend to maintain (or even increase) engine power while simultaneously lowering the emission. This trend conflicts to a degree with designs featuring lower numbers of cylinders and small engine displacements and so a new trend has been observed: the rightsizing trend [7].

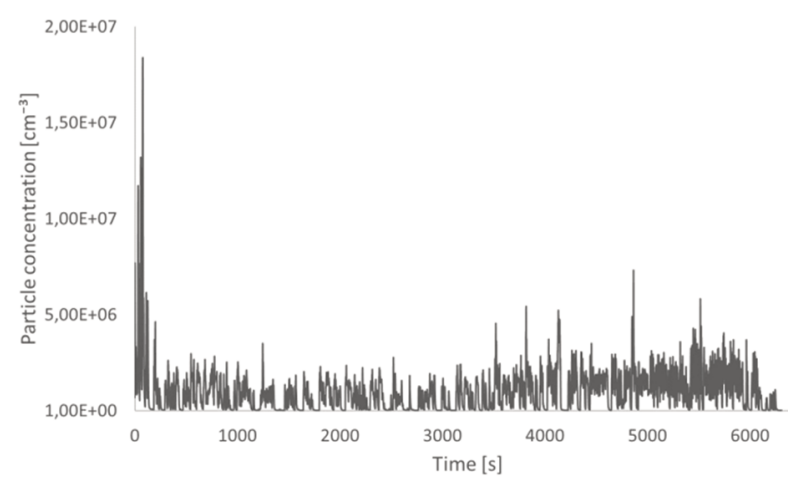

Fig. 6. Particle concentration during a 2-hour real driving (RDE) test with a GDI vehicle with no GPF installed [37]

Cold start of an engine, low temperature of the aftertreatment and an aggressive driving style are also factors influencing the intensity of NP emissions. Engine cold start occurs after a period of cooldown, where the powertrain is working below the optimal thermal states. This temperature strictly influences the distribution of lubricating oil in an engine $[35,36]$. Research conducted by BOSMAL on GDI vehicles with no GPF installed proved the domination of a cold start during real driving tests. PN concentrations were higher during cold start than during the next 2 hours of driving, even though later sections include high speed driving (Fig. 6). Various devices with different measuring ranges are available for quantifying $\mathrm{PN}$; particles in the range $10-23 \mathrm{~nm}$ are not counter by standard laboratory PN counters, yet the "missing" particles account for no more than $15 \%$ of the total for modern GDI vehicles [37].
Similarly, the research conducted by BOSMAL on Diesel-fuelled vehicles with DPFs proved that $57 \%$ of total PN were emitted during the first $\mathrm{km}$ of a cold start driving cycle at low ambient temperature $\left(-7^{\circ} \mathrm{C}\right)$, while at warmer ambient temperatures $\left(+25^{\circ} \mathrm{C}\right) 13 \%$ of total $\mathrm{PN}$ were emitted during the first $\mathrm{km}$ of driving. These numbers were lower for another vehicle without a DPF; $15 \%$ of the total PN quantity was emitted during the first $\mathrm{km}$ at $-7^{\circ} \mathrm{C}$ and $8 \%$ of the total PN were emitted over that distance at $+25^{\circ} \mathrm{C}$ [37]. Thus, lower ambient temperatures cause the NP emissions profile to become more "cold start-heavy". However, DPF-filtered PN levels are low and there can be considerable variation on behaviour from test to test and vehicle to vehicle.

Exhaust aftertreatment technologies based on filters (DPF, GPF) might be thought to be immune from cold start effects, yet cold start engine operation can still influence their performance. Firstly, cold devices have not yet expanded to their equilibrium volume seen under hot conditions and so there can be some leakage of unfiltered exhaust around the edge of the monolith or through cracks within it, which later close up as the monolith undergoes thermal expansion. Secondly, passive regeneration (unaided oxidation of soot trapped on the filter, especially on the upstream filter face - closest to the engine) is extremely unlikely to occur when the temperature of the system is low (i.e. immediately following cold start). And finally, cold start engine operation (especially at very low ambient temperatures) and driving during warmup generate greater amounts of soot than under other driving conditions, thereby increasing the need for more DPF frequent regenerations (and thus increasing total NP emissions because of the emissions associated with regeneration). For a GPF (where there is no active regeneration strategy), a build up of soot on the filter increases the backpressure, leading to increased fuel consumption and ultimately to more frequent regenerations (and thus increasing total NP emissions in the long term).

Such effects are of considerable importance in areas of low average ambient temperatures, especially in cold seasons. It was reported that the decreased temperature down to $-7^{\circ} \mathrm{C}$ may cause a $60-160 \%$ increase of NP emissions compared to the emission intensity at $23^{\circ} \mathrm{C}$ [29]. Ambient temperature aside, an aggressive driving style (i.e. high engine speeds and loads) causes increases in NP emissions [26]. Similarly, vehicle mass is an important factor influencing both pollution emission and fuel consumption (FC). It was reported that FC increases by $6-7 \%$ with an elevation of vehicle mass for each $100 \mathrm{~kg}$, which intensifies the emission of NPs.

\section{Conclusions}

There are many possibilities to reduce NP emissions associated with road transport. They include both technological aspects such a powertrain designs featuring advanced aftertreatment systems, production of new advanced fuels, as well as changes in social awareness such as promotion of eco-driving styles and propagation of information on the effects of NP pollution on the environment and human health.

It might appear that the problem of exhaust NP emissions from internal combustion engine-powered road transport has already been solved and that there is no need for further 
investigations. However, technological development both in the vehicle and engine industries, analytical chemistry and even medicine has proved the multi-disciplinary character of the problem. Thus, studies combining all three abovementioned disciplines remain in demand. The investigation of gaseous emissions is also a significant topic in this field, as they are the effect of preliminary processes of particle formation and thus might give more precise information on the biological impacts of PM and its origin.

Current EU legislation on emissions from light duty road vehicles covers emissions of $\mathrm{CO}_{2}, \mathrm{NO}_{\mathrm{x}}$, hydrocarbons and non-methane hydrocarbons, PN and PM. The technological development of instrumental techniques has enabled the detection of many other exhaust components which might significantly affect the human health which are not regulated by EU, US or other legislation. This creates some challenges both for engine and aftertreatment designers, fuel producers and scientists studying air quality and human health. The physicochemical laboratory methods used to generate the sample results presented in this paper represent a promising avenue for further research in the field of vehicular NP emissions.

\section{Acknowledgement}

The authors acknowledge the financial support of AGH University of Science and Technology (grant no. 15.11.210.452).

\section{Nomenclature}

\begin{tabular}{|c|c|c|c|}
\hline $\mathrm{AD}$ & aerodynamic diameter & $\mathrm{OC}$ & organic carbon \\
\hline ASC & ammonia slip catalyst & oxy-PAH & oxidative derivatives of $\mathrm{PAH}$ \\
\hline BSE & backscattered electron detector & PAH & polycyclic aromatic hydrocarbons \\
\hline DI & direct injection & PM & particulate matter \\
\hline DOCs & diesel oxidation catalysts & $\mathrm{PN}$ & particulate number \\
\hline DPFs & diesel particulate filters & RPM & revolutions per minute \\
\hline $\mathrm{EC}$ & elemental carbon & SCR & selective catalytic reduction \\
\hline EDS & energy dispersive X-ray spectrometer & SE & secondary electron detector \\
\hline EGR & exhaust gas recirculation & SEM & scanning electron microscopy \\
\hline FAPs & filtre à particules & TEM & transmission electron microscopy \\
\hline $\mathrm{FC}$ & fuel consumption & TWCs & three ways catalysts \\
\hline GDI & gasoline direct injection & VOCs & volatile organic compounds \\
\hline GPF & gasoline particulate filter & WHO & World Health Organisation \\
\hline LNT & lean $\mathrm{NO}_{\mathrm{x}}$ trap & WLTC & Worldwide harmonized Light vehicles Test \\
\hline nitro-PAH & nitric derivatives of $\mathrm{PAH}$ & & Procedures Cycle \\
\hline $\mathrm{NP}(\mathrm{s})$ & nanoparticle(s) & XPS & X-ray photoelectron spectroscopy \\
\hline
\end{tabular}

\section{Bibliography}

[1] STYSZKO, K., SAMEK, L., KISTLER, M. et al. Chemical characterization of PM10 from Krakow including heavy metals. Mercur Environ Identif Threat Hum Heal. 2013, 19-27.

[2] SZRAMOWIAT, K., STYSZKO, K., KISTLER, M. et al. Carbonaceous species in atmospheric aerosols from the Krakow area (Malopolska District): carbonaceous species dry deposition analysis. E3S Web Conf. 2016, 10.

[3] SZRAMOWIAT, K. The chemical characterization and identification of emission sources of atmospheric aerosols from the Kraków agglomeration. AGH University of Science and Technology. 2017.

[4] WHITBY, K.T. Proceedings of the International Symposium, The physical characteristics of sulfur aerosols. Atmos Environ. 1978, 12, 135-159. DOI:10.1016/0004-6981(78) 90196-8.

[5] SEINFELD J.H., PANDIS, S.N. Atmospheric chemistry and physics: from air pollution to climate change. John Wiley \& Sons. 1986.

[6] Aftertreatment systems design, development and evaluation of ICE n.d. http://www.en.clean-power.com.cn.

[7] BIELACZYC, P., WOODBURN, J. Current directions in LD powertrain technology in response to stringent exhaust emissions and fuel efficiency requirements. Combust Engines. 2016, 166, 62-75.

[8] KARJALAINEN, P., RÖNKKÖ, T., PIRJOLA, L. et al. Sulfur driven nucleation mode formation in diesel exhaust under transient driving conditions. Environ Sci Technol. 2014, 48, 2336-2343. doi:10.1021/es405009g.

[9] SWANSON, J.J., KITTELSON, D.B., WATTS, W.F. et al. Influence of storage and release on particle emissions from new and used CRTs. Atmos Environ. 2009, 43, 3998-4004. DOI:10.1016/j.atmosenv.2009.05.019.

[10] KITTELSON, D.B. Engines and nanoparticles: a review. J Aerosol Sci. 1998, 29, 575-588. DOI:10.1016/S00218502(97)10037-4.

[11] CZERWINSKI, J., MAYER, A., WICHSER, A. Effects of fuel tracing on nanoparticles from a Diesel engine. Combust Engines. 2015, 160, 3-10.

[12] ROTH, M., USEMANN, J., BISIG, C. et al. Effects of gasoline and ethanol-gasoline exhaust exposure on human bronchial epithelial and natural killer cells in vitro. Toxicol Vitr. 2017, 45, 101-110. DOI:10.1016/J.TIV.2017.08.016.

[13] SZRAMOWIAT, K., STYSZKO, K., SAMEK, L. et al. Chemical composition of particles emitted from stationary and mobile sources. 2nd Int. Conf. Sustain. Energy Environ. Dev. (SEED'17), Kraków, Novemb. 14-17, 2017, 2017.

[14] WHO. Review of evidence on health aspects of air pollution -REVIHAAP Project Technical Report. 2013.

[15] STYSZKO, K., SAMEK, L., SZRAMOWIAT, K. et al. Oxidative potential of PM10 and PM2.5 collected at high air pollution site related to chemical composition: Krakow case study. Air Qual Atmos Heal. 2017. DOI:10.1007/s11869017-0499-3.

[16] BERENT, K., FARYNA, M. High resolution EBSD/SEM analysis of PLZT ferroelectric crystals in low vacuum conditions - a few practical remarks. Solid State Phenom. 2012, 186, 62-65. DOI:10.4028/www.scientific.net/ssp. 186.62.

[17] YANG, H., LI, X., WANG, Y. et al. Experimental investigation into the oxidation reactivity and nanostructure of particulate matter from diesel engine fuelled with die- 
sel/polyoxymethylene dimethyl ethers blends. Sci Rep. 2016, 6, 37611

[18] POTENZA, M., MILANESE, M., DE RISI, A. Effect of injection strategies on particulate matter structures of a turbocharged GDI engine. Fuel. 2019, 237, 413-428. DOI:10.1016/j.fuel.2018.09.130.

[19] Fabiańska, M., Kozielska, B., Bielaczyc, P. et al. Geochemical markers and polycyclic aromatic hydrocarbons in solvent extracts from diesel engine particulate matter. Environ $\mathrm{Sci}$ Pollut Res Int. 2016, 23, 6999-7011. DOI: 10.1007/s11356015-5996-z.

[20] KORZENIEWSKA, A., SZRAMOWIAT, K., GOŁAŚ, J. An overview of the challenges in the studies of solid particle emission. 2nd Int. Conf. Sustain. Energy Environ. Dev. (SEED'17), Kraków, Novemb. 14-17, 2017, 2017.

[21] SZRAMOWIAT, K., STYSZKO, K., SAMEK, L. et al. The effect of fuel applied on the chemical composition of PM generated in combustion processes. 2018.

[22] LIATI, A., DIMOPOULOS EGGENSCHWILER, P., MÜLLER GUBLER, E. et al. Investigation of diesel ash particulate matter: A scanning electron microscope and transmission electron microscope study. Atmos Environ. 2012, 49, 391-402. DOI:10.1016/j.atmosenv.2011.10.035.

[23] GENGA, A., BAGLIVI, F., SICILIANO, M. et al. SEMEDS investigation on PM10 data collected in Central Italy: principal component analysis and hierarchical cluster analysis. Chem Cent J. 2012, 6, Suppl 2, S3-S3. DOI: 10.1186/1752-153X-6-S2-S3.

[24] QUEROL, X., PEY, J., MINGUILLÓN, M.C. et al. PM speciation and sources in Mexico during the MILAGRO2006 Campaign. Atmos Chem Phys. 2008, 8, 111-128. DOI:10.5194/acp-8-111-2008.

[25] ALANEN, J., SAUKKO, E., LEHTORANTA, K. et al. The formation and physical properties of the particle emissions from a natural gas engine. Fuel. 2015, 162, 155-161. doi:10.1016/j.fuel.2015.09.003.

[26] GIECHASKIEL, B., RICCOBONO, F., VLACHOS, T. et al. Vehicle emission factors of solid nanoparticles in the laboratory and on the road using Portable Emission Measurement Systems (PEMS). Front Environ Sci. 2015, 3, 82.

[27] BIELACZYC, P., WOODBURN, J., SZCZOTKA, A. Investigations into Particulate Emissions from Euro 5 passenger cars

Katarzyna Szramowiat, DEng. - Faculty of Energy and Fuels, AGH University of Science and Technology, Poland.

e-mail: Katarzyna.Szramowiat@agh.edu.pl

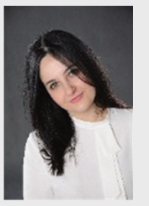

Wiktor Pacura, MEng. - Faculty of Energy and Fuels, AGH University of Science and Technology, Poland.

e-mail:WPacura@agh.edu.pl

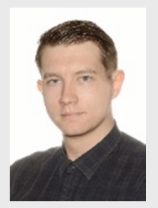

Piotr Bielaczyc, DEng. - BOSMAL Automotive Research And Development Institute Ltd in BielskoBiała, Poland.

e-mail: Piotr.Bielaczyc@bosmal.com.pl with DISI engines tested at multiple ambient temperatures. SAE Technical Paper. 2015. DOI: 10.4271/2015-24-2517.

[28] BIELACZYC, P., SZCZOTKA, A., WOODBURN, J. Investigations into exhaust particulate emissions from multiple vehicle types running on two chassis dynamometer driving cycles. $S A E$ Technical Paper. 2017. DOI: 10.4271/2017-01-1007.

[29] FUSHIMI, A., KONDO, Y., KOBAYASHI, S. et at. Chemical composition and source of fine and nanoparticles from recent direct injection gasoline passenger cars: Effects of fuel and ambient temperature. Atmos Environ. 2016, 124, 77-84. DOI:10.1016/j.atmosenv.2015.11.017.

[30] KŘŮMAL, K., MIKUŠKA, P., VEČEŘA, Z. Polycyclic aromatic hydrocarbons and hopanes in PM1 aerosols in urban areas. Atmos Environ. 2013, 67, 27-37. DOI:10.1016/ j.atmosenv.2012.10.033.

[31] SCHAUER, J.J., LOUGH, G.C., SHAFER, M.M. et al. Characterization of metals emitted from motor vehicles. Res Rep Health Eff Inst. 2006, 133, 1-76.

[32] MATĚJKA, V., METINÖZ, I., WAHLSTRÖM, J. et al. On the running-in of brake pads and discs for dyno bench tests. Tribol Int. 2017, 115, 424-431. DOI:10.1016/j.triboint.2017. 06.008.

[33] KUMAR, P., PIRJOLA, L., KETZEL, M., HARRISON, R.M. Nanoparticle emissions from 11 non-vehicle exhaust sources - A review. Atmos Environ. 2013, 67, 252-277. DOI:10.1016/j.atmosenv.2012.11.011.

[34] HEDBERG, Y.S., HEDBERG, J.F., ISAKSSON, S. et al. Nanoparticles of WC-Co, WC, $\mathrm{Co}$ and $\mathrm{Cu}$ of relevance for traffic wear particles - Particle stability and reactivity in synthetic surface water and influence of humic matter. Environ Pollut. 2017, 224, 275-288. DOI:10.1016/j.envpol. 2017.02.006

[35] BIELACZYC, P., WOODBURN, J., KLIMKIEWICZ, D. et al. An examination of the effect of ethanol-gasoline blends' physicochemical properties on emissions from a light-duty spark ignition engine. Fuel Process Technol. 2013, 107, 5063. DOI:10.1016/j.fuproc.2012.07.030.

[36] BIELACZYC, P., WOODBURN, J., SZCZOTKA, A., PAJDOWSKI, P. The impact of alternative fuels on fuel consumption and exhaust emissions of greenhouse gases from vehicles featuring SI engines. Energy Procedia. 2015, 66, 21-24. DOI:10.1016/j.egypro.2015.02.011.

[37] BOSMAL Automotive Research and Development Institute. Unpublished data. 2018.

Joseph Woodburn, MSci - BOSMAL Automotive Research and Development Institute Ltd in BielskoBiała, Poland.

e-mail: Joseph.Woodburn@bosmal.com.pl

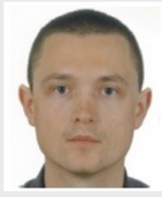

Katarzyna Berent, DEng. - Academic Centre for Materials and Nanotechnology, AGH University of Science and Technology, Poland.

e-mail: KBerent@agh.edu.pl

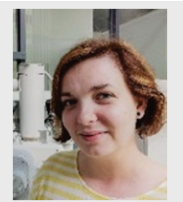

Prof. Janusz Gołaś - Faculty of Energy and Fuels, AGH University of Science and Technology, Poland.

e-mail:JGolas@agh.edu.pl

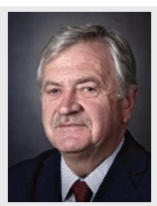

